\title{
How Does the Future Look?
}

\author{
by Ruy de Carvalho*
}

The Geneva Association is commemorating its 25th anniversary. During the last 25 years, insurance business has probably experienced its most significant changes of all times. Who could guess most of these changes 25 years ago?

How will insurance look 25 years from now? It's almost impossible to predict because we really stand on the threshold of a "New Global Age", as it was referred in a recent OECD report ${ }^{1}$. Nevertheless it may be useful to point out some ideas for an open debate, that may contribute to building the future.

Economic environment is changing rapidly and insurance has been trying to adapt to the new parameters and to cope with a different kind of risks, both in size, nature and uncertainty. The political, social, ethical and economic evolution is largely due to the progress of science and technology. It's clear that it is not science and technology itself that will determine the character of our society, but mainly our decisions about how to use it. Even if the aim of progress achieved in S\&T is oriented at risk avoidance, sometimes the solutions adopted create new risks. In fact, some risks are generated by the process of modernisation which, in turn, try to control them. This is particularly evident in areas like environment protection and health maintenance.

These new risks that characterise the so-called "risk society" are, of course, increasing insurance demand but they are also a challenge for insurers. For a long time, insurance was closely connected to the notion of time (the medium and long term approach); then it had an intimate relationship with space (gradual abolition of boundaries). At present, insurance is influenced by distance fading (intense use of information technologies in connection with telecommunications).

* Honorary Chairman, Associação Portuguesa de Seguradores.

1 "The World in 2020 - Towards a New Global Age"; OECD 1997. 
Looking into the future, three basic ideas can be to put forward:

- insurance is becoming a "full-range service";

- a "new competition" is emerging;

- successful management requires some "preconditions", new skills and cool reactions.

A "full-range service" has to be based on add-value and means much more than just redistribution or packaging of risks, or paying claims. It means increasing quality, technical skills and innovating products (well adapted to new kinds of risks and customers' demand). It also means taking advantage of the new public-private roles, recreating a good image based on transparency and ethical principles (not forgetting shareholder's expectations), paying special attention to the mix of the different sales channels.

The right choices in distribution could be one of the most significant keys for success. On the other hand, a full-range service requires full-scale training of employees, in order to develop the concept of a skilful front-office.

In addition, something to be taken into consideration is the importance of the socalled "emotions marketing", which is connected to a more sensitive consumer's behaviour that can be expected in the future.

All of this, and the new importance of asset management in insurance industry, raised also by the explosion of pension funds, is forcing insurance companies into less familiar territories, which requires adequate financial and investments skills.

The "new competition" in Europe is, at present, closely related to the consequences of the new single currency. Mergers and acquisitions (some of them are really redefining world finance), new regulatory and supervision rules, financial priorities (including "financial" solutions for unusually large risks such as natural or "provoked" catastrophes, or even the insurance cover against the risk of future soccer world cups being cancelled!) and capacity to anticipate the best use of new technologies, are daily examples of those consequences.

On the other hand, the post-Euro conditions are already more important than the Euro preparations themselves. This means coming back to strategic decisions, once the technical changes would be completed.

New competition also arises because boundaries in financial services are being pushed out. Some recent examples tend to prove that financial conglomerates can provide a better and wider range of services to customers and, at the same time, conserving the specificity of the activities of insurance companies, banks and investment societies. This means that between insurance and banking industries it's time for co-operation, not for confrontation. That's why bancassurance in Europe is an increasing model for groups. If there is any matter of concern about financial conglomerates, it should be much more on the regulatory and supervision side and not at an institutional level.

One question may be asked: what does "big" really means today in terms of financial industry?

The deal recently announced between Citybank and Travelers will create a group with a market capitalisation of $\$ 155 \mathrm{bn} ., 161.700$ employees and 100 million costumers in 
100 countries. Even if this is an unusual deal, others will probably follow. If so, "big" will have a different meaning in the future. It is a serious warning for medium-size undertakings.

The "preconditions" for successful management must refer to subjects like the relationship between insurance managers and the different insurance network players (customers, intermediaries, supervisory authorities, employees, suppliers and - very important - shareholders).

Insurance management has to deal with these kinds of interests, not always coincident, and try to make them converge. That will demand talent and technical, financial, investment and communication skills.

In the future, managing an insurance company will be an "art", that also requires constant and serious attention to markets' and others' judgements. Markets will react on the basis of information - statistical, accounting and others - provided by the entrepreneurs but "others" will react on a different basis (notations given by rating agencies could be one of them, but the pressure of a different conception of consumers' rights can be another one).

Putting together the problem of consumers' rights and the above mentioned debate on public-private roles, take us to the very sensitive point of the "social role" of insurance. In spite of the "humanistic aspect" that insurance was always ready to incorporate, a crucial distinction has to be made: insurance can not to be asked to play any kind of redistribution role, which is exclusively reserved to governments.

The ideas expressed can be resumed as follows:

- the number of insurance players tend to decrease; their size tends to increase;

- the relation between insurers and their customers are changing rapidly; there will be a strong investment in communication, distribution will be a key issue and a "full-range service" is an important competitive advantage in the insurance industry;

- as products are an effective way to communicate with clients, a strong emphasis on mass risks is to be expected;

- as competition is also between different financial sectors, many chances for the financial conglomerates will emerge; at the same time an increasing number of risks of very different kinds will be shifting from the public to the private sector, creating new opportunities, but also new concerns for those conglomerates;

- on the global environment, supervisory authorities will have to change methods and define new rules of control, but these changes must be realistic and both carefully and gradually implemented;

- to win the "cost's battle", insurers have to privilege technical accuracy, high quality and constant innovation, both on products and methods; new financial skills will be required because financial results will be determinant in a global and very competitive environment;

- insurance will continue to develop an "humanistic approach" that can not be mistaken with any kind of "redistribution role" which belongs exclusively to governments. 
In the years to come, insurance will probably be a new kind of business, based on significantly different skills and innovating management approaches. Its image has never been clearly understood, which means that it has to be better explained in an easier and transparent way. Now that insurance is entering new and very sensitive fields, this becomes even more important. It is a crucial point that insurers, supervisory authorities and governments have to take in due consideration. Insurance image must also be in accordance with the unique role insurance is playing in present economic and social life. If there is a sentence to resume the prospects in terms of insurance image, it should be something like : "in insurance we trust".

Insurance and its image must follow (if not leading) the reality of a new era. It is in the hands of insurance entrepreneurs to help to create this new reality, renewing a profession that despite existing for centuries needs to be in front of the future. 